\title{
On Growing Awareness and Change: Introduction to IJRSLCE, Volume 6
}

\author{
Lane Perry \\ Western Carolina University \\ Dan Richard \\ University of North Florida
}

As Heraclitus noted, "all things change." This constant change is expressed in the needs and experiences of students, faculty, and community partners, who, as key partners of the service-learning and community engagement (SLCE) space, continue to evolve. As learning and teaching environments change, as the needs of community partners shift, and as SLCE practices evolve, investigations into how to move forward in more intentional and effective ways are of critical importance. Einstein described insanity as doing the same thing over and over again but expecting different results. The same is potentially true when one does the same thing over and over again in a dynamic environment such as SLCE and expects the the same results. As students, institutions, communities, pedagogy, and learning environments continue to develop, so too must the practices and understanding of the critical elements of SLCE. This issue seeks to address and better understand this evolution.

\section{Advances in Theory and Methodology}

Change often brings new awareness, new perspectives on phenomena that had previously gone unnoticed. In "A Simple, Practical Framework for Organizing Relationship-Based Reciprocity in Service-Learning Experiences: Insights from Anthropology," Elaine Bennett challenges readers to reconsider the framework for understanding reciprocity in service-learning and community engagement. Using a case-study method, the author employs concepts of relationship-based reciprocity borrowed from anthropology to propose an integrated framework - based on key questions about objectives, structures, and outcomes - for understanding reciprocal relationships.

This section also includes two advances in measurement that reflect the shifting understanding of the complexity of student learning in SLCE. In "The BACE Scale: A New Measure for Assessing the Benefits of Community Engagement," Lee Miller, Sanjay Mehta, and Joyce McCauley test a model of perceived student benefits from community service-learning. The authors found that students perceived two dimensions associated with student benefits: personal development and social responsibility. Robert Bringle, Ashley Hedgepath, and Elizabeth Wall, in "I Am So Angry I Could ... Help!': The Nature of Empathic Anger," explore a new concept in the service-learning literature, empathic anger, a negative emotional state resulting from connecting with others who are suffering or experiencing injustice. In SLCE work, scholars and practitioners tend to focus on the more sympathetic and compassionate dimensions of empathy. Bringle and colleagues used a revised version of the Trait Empathic Anger scale (Vitaglione \& Barnett, 2003) and demonstrated that empathic anger was associated with civic engagement orientations and concern for social justice. These quality investigations set the stage for new research on the impact of SLCE. 
2 | International Journal of Research on Service-Learning and Community Engagement

\section{Community Partnerships and Impacts}

This section serves as a response to the clarion call sent up in 2017 by Alan H. Bloomgarden in his "Out of the Armchair: About Community Impact." In this article, Bloomgarden stated that "we need this inquiry [with community] to focus ourselves, our students, and our institutions squarely upon wider societal concerns that have not only great urgency and significance on their own, but also pervasive implications for our capacity to continue and advance community-engaged practices and partnerships" (p. 22). Such inquiries can be conducted reciprocally and have reciprocally valuable results for advancing SLCE efforts. In this section, Cecilia Orphan, Deborah Romero, and Liliana Diaz-Solodukhin, in their article "Fostering Collective Impact: Measuring and Advancing Higher Education's Contributions to Civic Health and Equity in Colorado," demonstrate how the concept of collective impact can be applied within the SLCE field and can help support reciprocal partnerships between universities and community leaders aimed at assessing campus-community engagement.

\section{Faculty Roles and Institutional Issues}

Higher education faces a new reality: the increased reliance on full-time, non-tenure-track faculty. Many of these faculty members rise above considerable institutional challenges and focus on servicelearning pedagogy. In '“Cutting-Edge' or 'Ridiculously Isolated'?: Charting the Identities, Experiences, and Perspectives of Full-Time, Non-Tenure-Track Faculty Engaged in ServiceLearning," Paul H. Matthews and Shannon O. Wilder address this often overlooked population. In their phenomenological investigation of the identities and roles of non-tenure-track faculty, the authors found that despite isolation and lack of support from their institutions, non-tenure-track faculty continue to pursue service-learning as a teaching strategy, in part because they value its impact on their teaching practice. The changing landscape of faculty roles at higher education institutions will likely foster new avenues for research, new faculty populations, and new questions to be explored.

\section{International Service-Learning and Community Engagement Research}

The international section of an international journal is a likely place to have one's assumptions challenged. In "The Global and the Local: Programs that Predict Critical Thinking and Cultural Appreciation Development in Students," Christopher Johnstone, Krista Soria, Tiago Bittencourt, and Millicent Adjei explore the impact of international study-abroad experiences and multicultural servicelearning experiences. The authors questioned whether the same positive impacts on cultural appreciation and critical thinking observed in intensive study-abroad programs could be achieved through less expensive, local service-learning experiences at home. They found that long-term domestic programs that involve cross-cultural experiences achieved positive learning outcomes similar to those of international experiences. These findings pose new questions and challenging perspectives for future research to address.

This section also includes Ajanaw Alemie Desta and Hone Mandefro Belay's "Nature, Benefits, Challenges, and Opportunities of University-Community Engagement at the University of Gondar, Ethiopia: A Case Study," which uses a case-study method and thematic analysis to illuminate the benefits and challenges of university-community engagement. Researchers interviewed community partners as well as university stakeholders engaged in partnerships. Their analysis confirmed many themes relevant to the SLCE literature, including the benefits of mutual partnerships to university and community stakeholders and the challenges associated with academic culture and power imbalances in reciprocal relationships. 


\section{Student Outcomes (Primary, Secondary, and Higher Education)}

Students change across generations, and teaching approaches, learning environments, and communities change along with them. In this section, the complexities of addressing student outcomes are explored in nine research studies: "Service-Learning: A Powerful Pedagogy for Promoting Academic Success Among Students of Color" by Michelle Sterk-Barrett and Isabelle Jenkins; "Transformative Learning for Peer Mentors Connected to a Postsecondary Education Program for Students with Intellectual and Developmental Disabilities" by Melinda Gibbons, Arden Szepe, Laura S. Wehat, and Anna Lora Taylor; "Early Exposure to Service-Learning and College Success Beyond the Freshman Year" by Wei Song, Andrew Furco, Geoffrey Maruyama, and Isabel Lopez; "The Impact of Community Service-Learning in a Rural Community on Undergraduate Students" by Lauren Paulson; "Service Experiences of Undergraduate Engineers" by Rachel Rupnow, Kirsten Davis, Rachelle Johnson, Elizabeth Kirchner, Jyotsana Sharma, and Shahidur Rashid Talukdar; "Pinning the Gap Between SOTL and SLCE" by Amy Burden; "Exposing Vocabulary Learning in ServiceLearning" by Laura Walls and C. Cecelia Tocaimaza-Hatch; "The Impact of Action Civics ServiceLearning on Eighth-Grade Students' Civic Outcomes" by Steven Hart and Christian Wandeler; and "Advancing Civic Science through University Students' Service-Learning with Youth" by Alisa Pykett, Dorothea Ledin, Constance Flanagan, and Claire Barrett.

It is clear from even a cursory review of these articles - and would be incontestable from an in-depth reading - that research into student outcomes within the primary, secondary, and higher education contexts is digging deeper into typically underrepresented or misunderstood populations and contexts. This is indicative of the value the field places on informed practices with all populations, at all levels, and in as many ways as possible. Informed practice can lead to greater impact, and this section can help do just that.

\section{Conclusion and Thank You}

We are indebted to the team of section editors, peer review board members, peer reviewers, and authors whose tireless efforts made this issue possible. Additionally, their dedicated approach helped inform the quality and quantity of valuable information and field shaping knowledge that this issue offers. Our field continues to grow and evolve in very thoughtful and intentional ways. We hope that this issue serves as a source of nourishment and guiding light for adaptation as we practitioners, scholars, and Community Engagement Professionals move forward into deeper, more thoughtful levels of our work.

\section{References}

Bloomgarden, A. (2017). Out of the armchair: About community impact. International Journal of Research on Service Learning and Community Engagement, 5(1), 21-23. Retrieved from: https://journals.sfu.ca/iarslce/index.php/journal/article/view/307/198

Vitaglione, G. D., \& Barnett, M. A. (2003). Assessing a new dimension of empathy: Empathic anger as a predictor of helping and punishing desires. Motivation and Emotion, 27(4), 301-325. 